\title{
Coming full circle
}

Since the advent of the first X-ray study in 1895, the options available in imaging technology have expanded dramatically with a similar rise in cost [1]. Determining the efficacy and appropriate use of imaging technology is, not surprisingly, a focus of cost containment. Of course, many conditions do benefit from modern technology to help make their diagnosis. Brain tumours for example can be confirmed in a noninvasive manner by CT or MRI. However, other conditions, in the hands of an expert clinician who has conducted a thorough history and physical examination, can often be diagnosed accurately and treated properly without the need for an imaging study. That expertise gleaned from years of clinical experience often gives senior physicians a prescient gestalt about who is sick or who has a certain diagnosis. These éminence grise could just look at a patient and scan the chart to declare accurately that the patient had condition ' $\mathrm{X}$ ' or was about to crash and needed to go emergently to the Intensive Care Unit or Operating Room. Ideally, if that expertise could be quantified and transformed into easily accessible rules it might help decrease the use of imaging and laboratory studies.

The study by Boettcher et al. [2] looked at the use of scrotal ultrasonography (US) in evaluating children with an acute scrotum. The authors identified several critical observations: acute duration, nausea and vomiting, abnormal cremasteric sign and high testicular position. These guidelines would reduce the use of scrotal US while decreasing the negative scrotal exploration rate by $55 \%$ but still maintaining a sensitivity of $100 \%$.

The Emergency Room (ER) has served before as the laboratory for this type of cost containment. In 1995, diagnostic rules were proposed to guide the ordering of X-rays for patients who presented to the ER with knee injuries. The 'Ottawa Knee Rules' identified five parameters where imaging would be needed: age $\geq 55$ years, tenderness at the fibular head, isolated patellar tenderness, inability to flex the knee to $90^{\circ}$, and inability to walk four weight-bearing steps after injury or in the ER [3-5]. Validation of the original proposals found a high sensitivity for knee fractures while decreasing the number of knee X-rays. A subsequent extension of these rules from Pittsburgh added the mechanism of injury, a different age filter $(<12$ and $>50$ years) and a hierarchy to the rules. These actions were found to increase the specificity while maintaining a very high sensitivity [6].
The key physical findings in the Boettcher et al. [2] study were conducted by specialist trainees or attendings (i.e. senior registrars/residents or consultants) of the paediatric surgery unit. The authors acknowledge that physicians who are not experienced with examining children might find the tasks of recognising a high riding testicle or an abnormal cremasteric reflex challenging; their application of the guidelines would be difficult. Could these same rules be applied as effectively by the everyday staff of the ER? Is it less cost efficient for the generalist to order a scrotal US than to have a specialist on-call in the ER? That may be the crucial next step, which brings the discussion full circle to why imaging studies and laboratory investigations are often ordered. They are a means to confirm an uncertain clinical diagnosis, especially among the less experienced or generalists. Cost containment will no doubt make such rules more prevalent. However, they cannot be enacted in isolation and one must hope that sufficient clinical training will exist to correctly and fully implement them; otherwise a useful diagnostic aid would be arbitrarily restricted at the potential detriment of the patient.

\section{Conflict of Interest}

None declared.

Julian Wan

Department of Urology, University of Michigan, Ann Arbor, MI, USA

e-mail: juliwan@umich.edu

\section{References}

1 Riesz PB. The life of Wilhelm Conrad Roentgen. AJR Am J Roentgenol 1995; 165: 1533-7

2 Boettcher M, Krebs T, Bergholz R, Wenke K, Aronson D, Reinshagen K. Clinical and sonographic features predict testicular torsion in children: a prospective study. BJU Int 2013; 112: 1201-6

3 Stiell IG, Greenberg GH, Wells GA et al. Prospective validation of a decision rule for the use of radiography in acute knee injuries. JAMA 1996; 275: 611-5

4 Stiell IG, Greenberg GH, Wells GA et al. Derivation of a decision rule for the use of radiography in acute knee injuries. Ann Emerg Med 1995; 26 : 405-13

5 Stiell IG, Wells GA, Hoag RH et al. Implementation of the Ottawa Knee Rule for the use of radiography in acute knee injuries. JAMA 1997; 278: 2075-9

6 Seaberg DC, Yealy DM, Lukens T, Auble T, Mathias S. Multicenter comparison of two clinical decision rules for the use of radiography in acute, high-risk knee injuries. Ann Emerg Med 1998; 32: 8-13 